\title{
Which Dynamic Rupture Parameters Can Be Estimated from Strong Ground Motion and Geodetic Data?
}

\author{
Sophie Peyrat ${ }^{1}, \mathrm{Kim}_{\text {B }}$ B. Olsen ${ }^{1}$, and Raúl Madariaga ${ }^{2}$
}

\begin{abstract}
We have tested to which extent commonly used dynamic rupture parameters can be resolved for a realistic earthquake scenario from all available observations. For this purpose we have generated three dynamic models of the Landers earthquake using a single, vertical, planar fault with heterogeneity in either the initial stress, the yield stress, or the slip-weakening distance. Although the dynamic parameters for these models are inherently different, all the simulations are in agreement with strong motion, GPS, InSAR, and field data for the event. The rupture propagation and slip distributions obtained for each model are similar, showing that the solution of the dynamic problem is non-unique. In other words, it is not always possible to separate strength drop and the slip-weakening distance using rupture modeling, in agreement with the conclusions by GuATTERI and SPUdich (2000).
\end{abstract}

Key words: Rupture dynamics, 1992 Landers earthquake, initial stress, friction law parameters, strong motion data, geodetic data.

\section{Introduction}

Earthquake rupture is initiated when the stress on a pre-existing fault reaches a critical level on a finite patch of the fault. After initiation the constitutive laws and the initial stress on the fault control how the earthquake propagates and arrests on the fault. Thus the initial stress $\left(T_{e}\right)$ and the parameters of the constitutive laws (the yield stress $T_{u}$ and the slip-weakening distance $D_{c}$ in our case) are usually used as the initial parameters in dynamic rupture models. In addition, rupture propagation is characterized by various other parameters, such as slip (in part observable in case of surface rupture) and slip velocity which is responsible for the generation of seismic waves as well as ground failure caused by the earthquake.

The level and variation of the initial stress and friction affects the slip, slip velocity and stress drop in a strongly nonlinear fashion, as demonstrated by simulations of dynamic rupture on heterogeneous faults (i.e., OLSEN et al., 1997; Peyrat et al., 2001). For example, larger values of the frictional parameters generate

\footnotetext{
${ }^{1}$ Institute for Crustal Studies, University of California, Santa Barbara, Santa Barbara, CA 931061100, U.S.A. E-mail: peyrat@crustal.ucsb.edu, kbolsen@crustal.ucsb.edu

${ }^{2}$ Laboratoire de Géologie, Ecole Normale Supérieure, 24 rue Lhomond, 75231 Paris Cedex 05, France. E-mail: madariag@geologie.ens.fr
} 
larger fracture energy $\left(G \propto\left(T_{u}-T_{f}\right) D_{c}\right.$, where $T_{f}$ is the kinematic friction) and therefore increase rupture resistance. On the other hand, larger values of the initial stress generate more available strain energy $\left(U \propto T_{e}^{2}\right)$ and promote rupture. In addition, for realistic scenarios where the initial conditions are heterogeneous the behavior of the rupture is rather difficult to estimate. The dynamic rupture and therefore the radiated waves are not only controlled by the values of the initial conditions, but also by the associated characteristic length scales.

Two classical and idealized models describe heterogeneous fault rupture. DAs and AKI (1977) proposed the barrier model, where the fault contains areas of increased rupture resistance. The nucleation occurs in a region of weak rupture resistance and the rupture propagates between barriers. Alternatively, KANAMORI and STEWART (1978) proposed the asperity model, where the fault contains areas of stress concentrations due to former earthquakes or aseismic slip. The barrier and asperity models are viewed as complementary in describing dynamic rupture propagation.

GUATTERI and SPUDICH (2000) demonstrated with a quasi-dynamical study that it is not possible to estimate strength drop and the slip weakening distance separately from low-frequency strong motion data $(<1.6 \mathrm{~Hz})$ only for a realistic earthquake through kinematic modeling. In our study we take a step further to examine to which extent the parameters can be estimated from trial-and-error inversion of dynamic rupture, in both cases of asperity and barrier models. The goal of this study is to understand the fundamental role of the different dynamic parameters involved during earthquake rupture, as well as their signature in seismic, geodetic and field data. Do barrier and asperity models generate differences in accelerograms, slip vectors, fringes in interferometric data and/or in surface slip? Which (if any) rupture parameters can we constrain from these types of observed data? In order to answer these questions, we use dynamic modeling of the M 7.3 June 28, 1992, Landers earthquake (Fig. 1), one of the largest, best-recorded strike-slip earthquakes in California.

In a first attempt at constructing a dynamic model of the Landers earthquake, OlsEN et al. (1997) studied the frictional conditions under which rupture could propagate and then modeled the dynamic rupture process for the initial stress field obtained from the slip distribution determined by WALD and HeAton (1994). PEYRAT et al. (2001) carried the initial study by OLSEN et al. (1997) a step further by inverting for the initial conditions on the fault using the observed ground motion. By trial-and-error inversion of strong motion data PEYRAT et al. (2001, 2002) constructed an asperity model (variable initial stress $T_{e}$ ) and a barrier model (variable yield stress $T_{u}$ ) for the Landers rupture. However, there is evidence from inversion of seismic data for large earthquakes (i.e., IDE and TAKEO, 1997, for the 1995 Kobe earthquake), that the slip-weakening distance $D_{c}$ may vary spatially. Therefore, we build an additional barrier model, with variable slip-weakening distance $D_{c}$, from trial-and-error inversion of strong motion data. The barrier and asperity models were related using the non-dimensional parameter $\kappa$ identified by MADARIAGA and OLSEN (2000) (see also DunHAM et al., 2003), which contains information about all the 


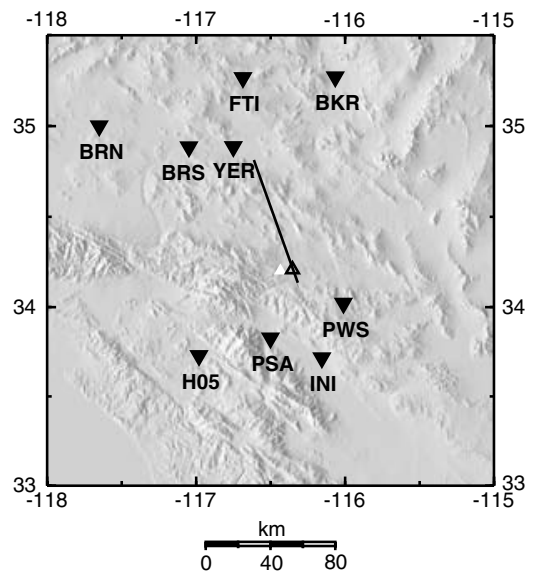

Figure 1

Map of the Landers earthquake region with the fault trace and the location of the strong motion stations (triangles) used in this study.

initial parameters studied here $\left(T_{e}, T_{u}\right.$ and $\left.D_{c}\right)$. GUATTERI and SPUDich (2000) used the fracture energy $G$ for this purpose, which however is insufficient for our dynamic models. Finally, in order to validate our models and examine the signature of these models in different measurable data sets, we compare the synthetic Global Positioning System (GPS), interferometric synthetic aperture radar (InSAR), and surface slip data for the three models to the measured data.

\section{Numerical Modeling Method and Friction Law}

We invert the seismic data for the Landers earthquake using a well-posed dynamic fault model, consisting of spontaneous rupture propagation along a vertical, planar fault. We solve the elastodynamic equation using a fourth-order staggered-grid finite difference method in a three-dimensional medium (MADARIAGA et al., 1998). The elastodynamic equations are combined with a free surface boundary condition at the top of the fault and absorbing boundary conditions introduced at the grid edges to eliminate artificial reflections. Finally, the fault is modeled as an internal boundary on which stress is related to slip by a friction law. Here we use the simple slip-weakening law

$$
T(D)=\left\{\begin{array}{ll}
\left(T_{u}-T_{f}\right)\left(1-\frac{D}{D_{c}}\right)+T_{f} & D \leq D_{c} \\
T_{f} & D>D_{c}
\end{array},\right.
$$

where $T_{u}$ is the yield stress, $T_{f}$ is the kinematic friction at high slip and $D_{c}$ is the slipweakening distance. This friction law was introduced by IDA (1972). Slip is zero until the stress reaches a peak value $\left(T_{u}\right)$; then it starts to increase while, simultaneously, 
stress decreases linearly to $T_{f}$ over the slip-weakening distance $D_{c}$. Furthermore, for the inversion, synthetic ground displacement time histories, band-pass filtered between 0.07 and $0.5 \mathrm{~Hz}$, are generated using a Green's function propagator method, which is more efficient than the FD method in the case of relatively large faultreceiver distances as in our study.

\section{Effect of Initial Parameters on Rupture Propagation}

Figure 2 illustrates the complexity of the horizontal slip rate generated from heterogeneities in the initial conditions for two sets of the initial stress $\left(T_{e 1}\right.$ and $\left.T_{e 2}\right)$, yield stress $\left(T_{u 1}\right.$ and $\left.T_{u 2}\right)$ and slip-weakening distance $\left(D_{c 1}\right.$ and $\left.D_{c 2}\right)$, compared to a homogeneous reference model. Clearly, small variations in the initial conditions generate large, nonlinear changes in the rupture history. We can generate different rupture histories with very similar initial conditions (for example, $T_{e 1}$ and $T_{e 2}$ ), and similar rupture histories with completely different models (for example, the asperity model with $T_{e l}$ and the barrier model with $D_{c l}$ ).

Figure 3 depicts significant differences between synthetics generated at the stations YER and PWS for the different initial conditions in Figure 2. Note in particular the strong effects of the initial conditions on the amplitudes in the forward rupture direction (YER) compared to those in the opposite direction (PWS), where the influence of the propagation path between the source and the receiver becomes more significant than the source itself. For this reason, and also due to their smaller amplitudes, stations located in the backward rupture direction are relatively more difficult to use in the rupture inversion. Finally, the observed seismic waveforms are
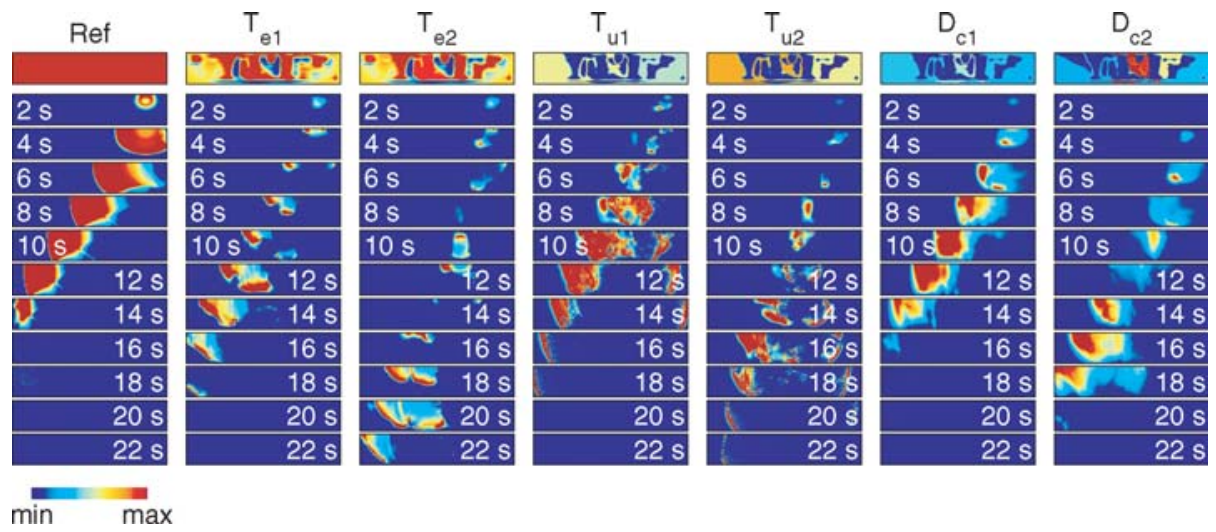

Figure 2

Influence of the initial parameters (top panels) on the horizontal slip rate history for six different heterogeneous models of the Landers earthquake. The other initial parameters for each model are kept constant over the fault. The figure on the left shows a reference model with homogeneous initial parameters. 


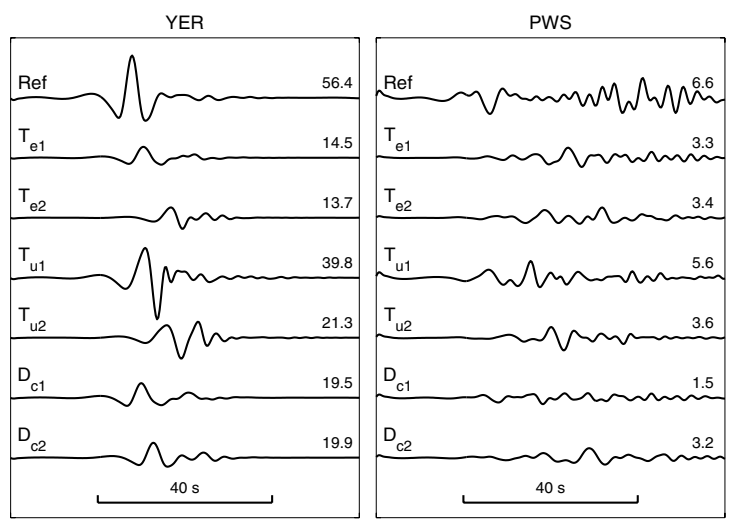

Figure 3

Horizontal east-west displacement time histories at stations YER and PWS (see Fig. 1) for the models shown in Figure 2. Amplitudes are marked to the right of each trace in centimeters.

temporal averages influenced by the entire rupture history. For example, the slip in the epicentral area is controlled mainly by the local stress decrease, whereas the slip toward the end of the fault is influenced by a longer time window of radiation. Similar effects can be seen for the other parameters, the yield stress and the slipweakening distance. In summary, the radiated waves are strongly sensitive to perturbations in the initial dynamic parameters.

\section{From Asperity to Barrier Model}

MADARIAGA and Olsen (2000) identified a non-dimensional parameter that contains all the initial dynamic rupture parameters discussed in this study and controls rupture,

$$
\kappa=\frac{T_{e}^{2} W}{\mu\left(T_{u}-T_{f}\right) D_{c}},
$$

where $W$ is a characteristic length scale. This parameter was derived from Griffith's criterion for shear faults and measures the ratio of the available strain energy $\left(U=T_{e}^{2} \mathrm{~W} / 2 \mu\right.$ to the energy release rate $\left(G=0.5\left(T_{u}-T_{f}\right) D_{c}\right)$. For small values of $\kappa$, rupture does not propagate because the Griffith's criterion is not satisfied. A bifurcation of the rupture occurs when $\kappa$ exceeds a critical value $\kappa_{c}$, beyond which rupture grows indefinitely. MADARIAGA and OLSEN (2000) estimated $\kappa_{c}$ at 0.7 and 0.8 for homogeneous asperity and barrier models, respectively. Thus, for models with similar $W$ (for homogeneous models equal to the half width of the fault, see MADARIAGA and OLSEN, 2000), $\kappa$ provides a means to relate asperity and barrier models (with $T_{f}=0 \mathrm{MPa}$ ) as 

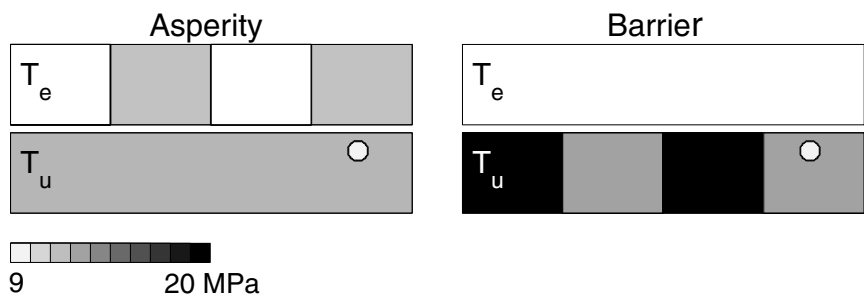

Sliprate history

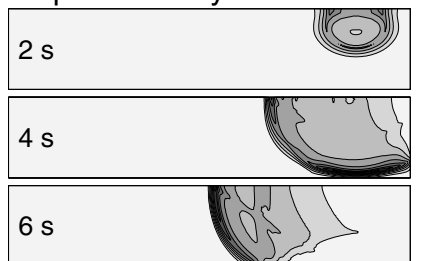

Sliprate history
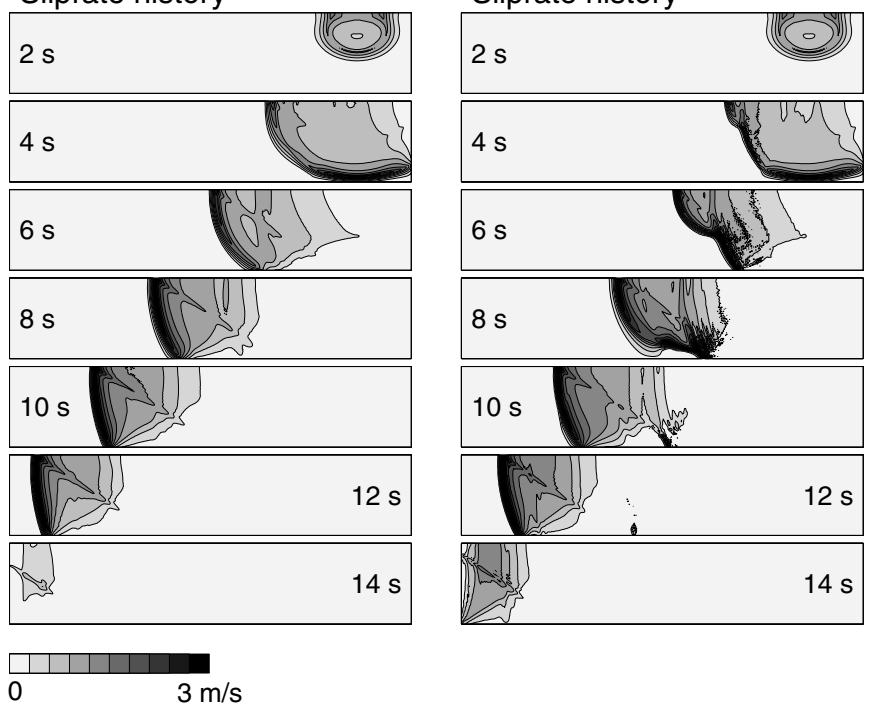

Figure 4

Comparison between the horizontal slip rate histories for two simple asperity and barrier models. $D_{c}$ is homogeneous and equal to $80 \mathrm{~cm}$ for both models. Rupture is initiated at the circle.

$$
\begin{aligned}
\kappa & \propto\left[\frac{T_{e}^{2}(x, y)}{T_{u} D_{c}}\right]_{\text {asperity }} \\
& \simeq\left[\frac{T_{e}^{2}}{T_{u}(x, y) D_{c}}\right]_{\text {barrier }} \\
& \simeq\left[\frac{T_{e}^{2}}{T_{u} D_{c}(x, y)}\right]_{\text {barrier }}
\end{aligned}
$$

In other words, the model of rupture propagation in asperity and barrier models should be similar when the values of $\kappa$ are identical.

However, the problem is more complicated in the heterogeneous case. Figure 4 shows rupture propagation for simple barrier and asperity models derived from Equation 3 assuming constant $W$ and constant $D_{c}$. It is clear that the rupture propagations for the two models are appreciably different (for example at $6 \mathrm{~s}$ ), 

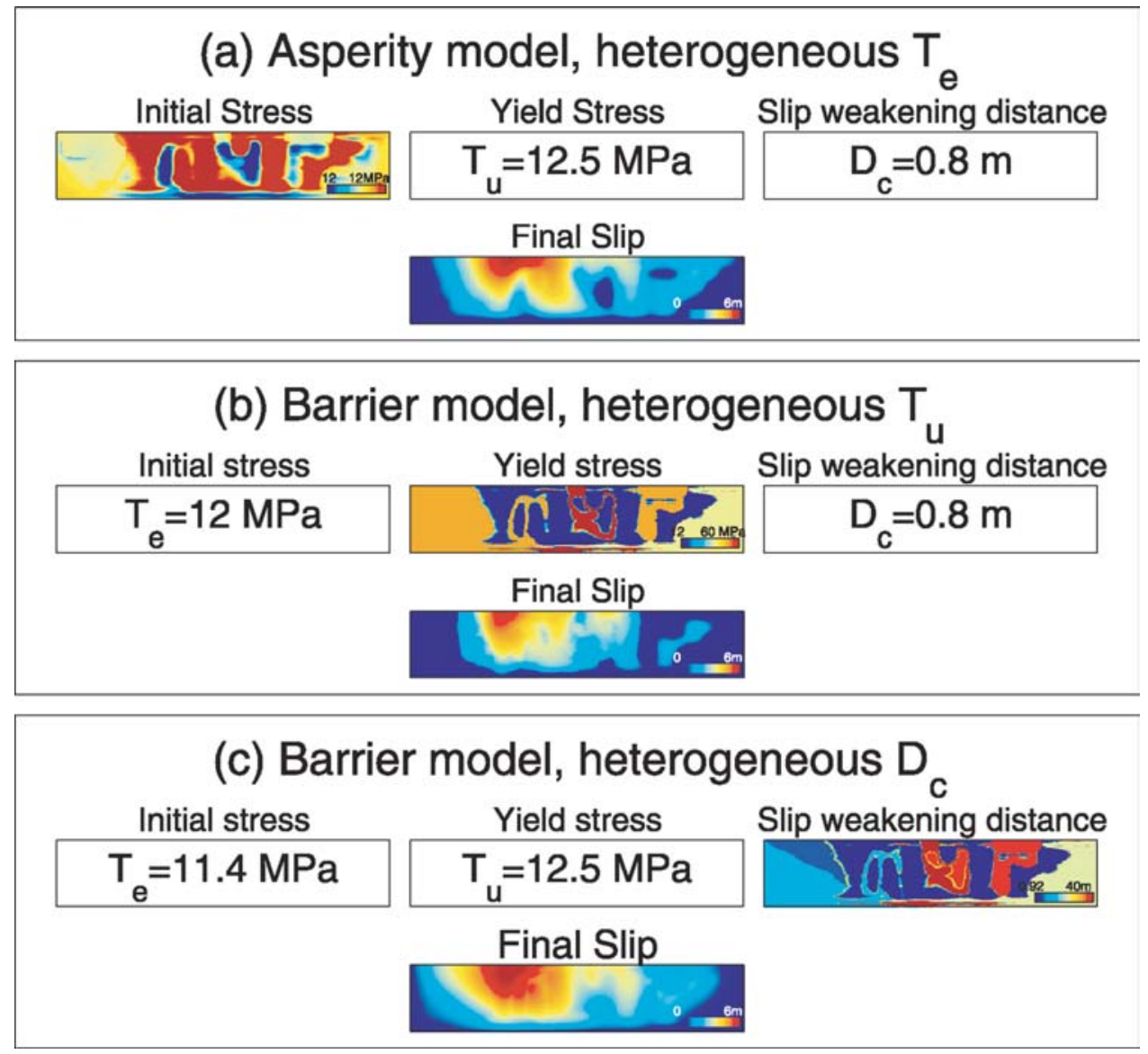

Figure 5

Initial conditions and final slip distribution for (a) the asperity model with spatially variable initial stress, (b) the barrier model with spatially variable yield stress, and (c) the barrier model with spatially variable $D_{c}$.

suggesting that the latter assumption is incorrect. Besides, Figure 4 shows smaller differences between the two models further away from the hypocenter. Thus, the values of $W$ could possibly be a function of the distance to the hypocenter (G. BEROzA, personal communication, 2000). In any case we expect $W$ to be a representation of the size of the heterogeneities and their correlation length.

PeYRat et al. $(2001,2002)$ constructed a barrier model $\left(T_{u}\right.$ variable $)$ from their asperity model ( $T_{e}$ variable) of the 1992 Landers earthquake using Equation (3). Due to the unknown values of $W$, additional inversion of recorded accelerograms was required to obtain a satisfactory fit between recorded and synthetic accelerograms from the barrier model. In a similar fashion we generate here an additional barrier model with variable $D_{c}$. Figure 5 shows the initial conditions of these three 
complementary dynamic models. The two barrier models manifest larger and more abrupt variations in their parameter distribution than is the case for the asperity model. We realize that these large values of $D_{c}$ are arguable. Nevertheless, such values of $D_{c}$ and $T_{u}$ are necessary to control rupture propagation in these barrier models. The values of the patches control the path along which rupture propagates for the asperity model and the path where rupture does not propagate for the barrier model. However, the problem of determining the strength of the barriers remains. The straightforward assumption is to assign as large a strength as possible and still promote rupture around these barriers. For example, in a barrier model with variable $T_{u}$, how large values of the maximum yield stress can be imposed and still retain rupture propagation? However, different values of the maximum $T_{u}$ will generate different rupture histories: the smaller the values of $T_{u}$ the faster the rupture speed and the larger the slip velocity amplitude, if the level of rupture resistance is sufficiently low to allow rupture to propagate. In the case of the barrier model we find very large values of the maximum $D_{c}$ which prevent rupture in these patches but allow rupture to propagate around, complicating the trial and error inversion considerably. Rupture seems more sensitive to small variations in the values of the slip-weakening distance compared to the yield stress.

Our three dynamic models generate similar rupture histories (Fig. 6, top) and slip distributions (Fig. 5), i.e., there are no major differences between the asperity model and the barrier models even though the initial conditions are completely different. The only difference is that the barrier model with $T_{u}$ variable generates a higher frequency response due to the higher stress drop. For all models rupture follows a complex path over the fault, showing a confined band of slip propagating unilaterally toward the northwestern part of the fault, before arrest after about $21 \mathrm{~s}$. The complex rupture path and the healing are consequences of the spatial heterogeneities of different initial parameters as originally suggested by BEROZA and MIKUMO (1996). Figure 7 shows a comparison between ground displacement time histories for data and synthetics calculated from the rupture propagation obtained for the three models used in the trial-and-error inversion. The overall waveforms are well reproduced by the synthetics, and the best fits are obtained for stations in the forward rupture direction (YER, BRS, and FTI). Thus we have computed three mechanical models of the rupture propagation which satisfy observed accelerograms.

\section{Comparison to Geodetic and Field Data}

The rupture inversion of the Landers earthquake was carried out using strong motion data only. However, additional observed data may help constrain the rupture model. For example, HernANDEz et al. (1999) used simultaneous inversion of interferometric synthetic aperture radar (InSAR), Global Positioning System (GPS), and strong motion data to obtain a kinematic model of the event. Both GPS and 
Asperity model

(a) Heterogeneous $\mathrm{T}_{e}$
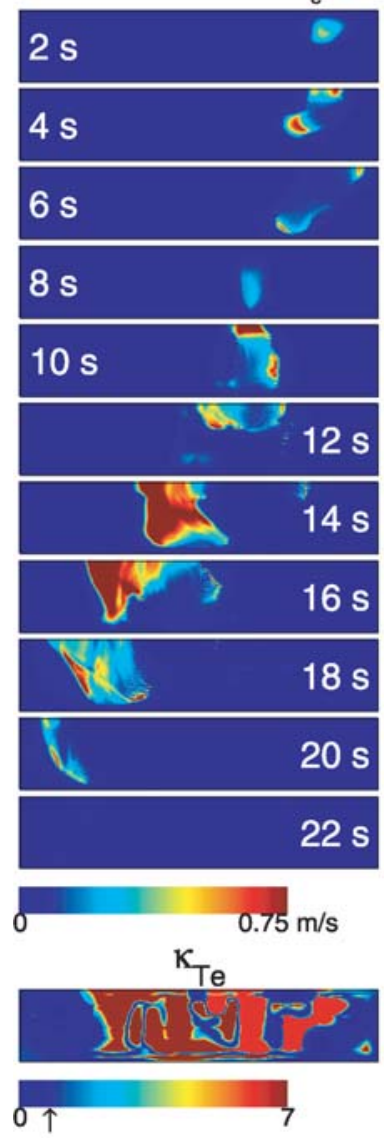

\section{Barrier models}

(b) Heterogeneous $T_{u}$
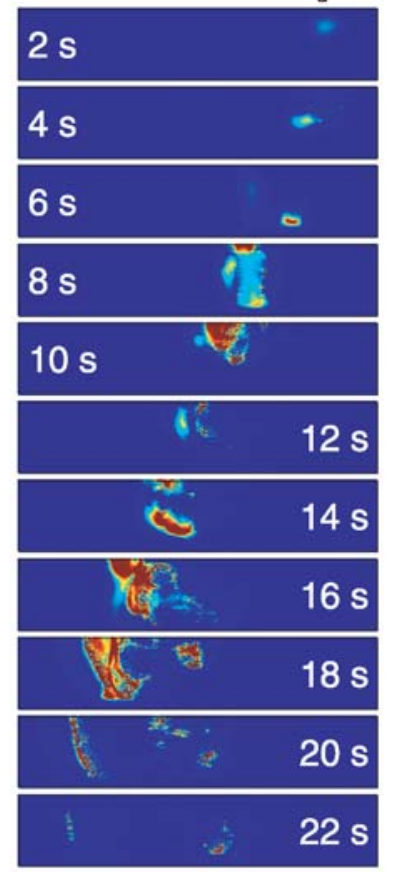

(c) Heterogeneous $D_{c}$
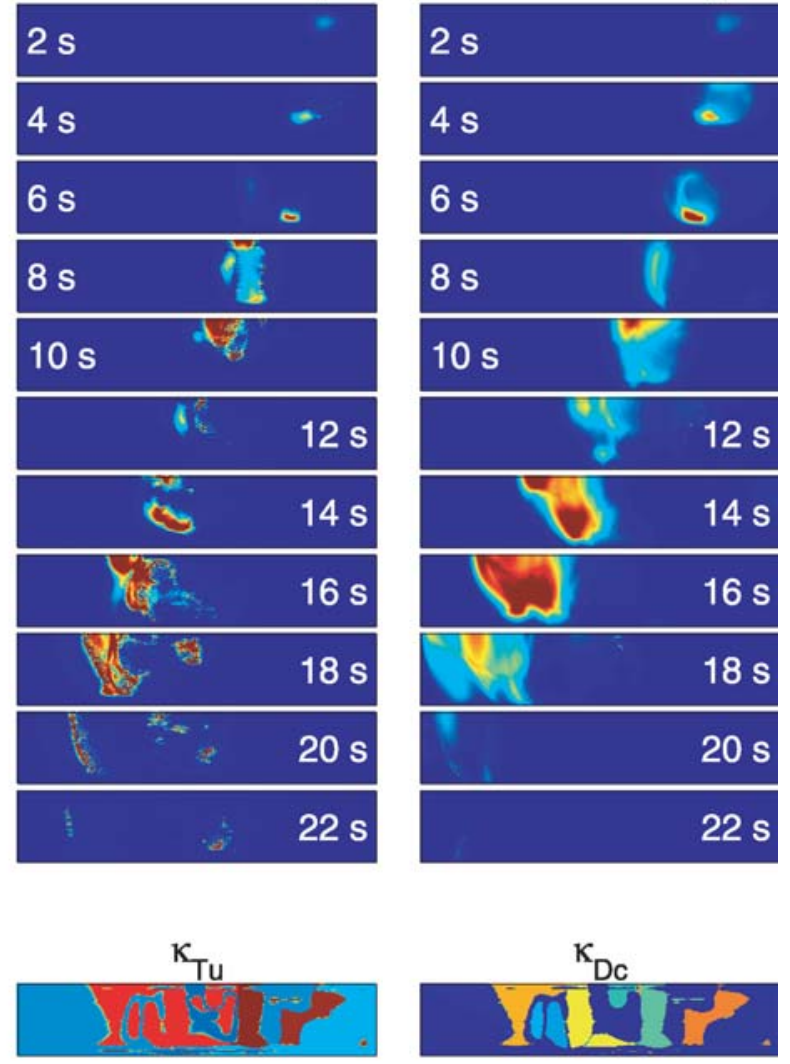

Figure 6

Rupture history for the three complementary models of the Landers earthquake. (Top) Each snapshot depicts the horizontal slip rate on the fault at $2 \mathrm{~s}$ time intervals. (Bottom) $\kappa$ distributions over the fault. The arrow depicts an average value of $\kappa_{c}$ estimated by MADARIAGA and OLSEN (2000) for homogeneous asperity and barrier models.

SAR data allow estimates of relative displacements of the ground during an earthquake, without prior knowledge of the location of the event. SAR interferometry was used by MASSONNET et al. (1993) to capture the movements produced by the Landers earthquake. Such data complement strong motion seismic data in their dense spatial sampling. The interferogram was constructed by combining topographic information with SAR images obtained by the ERS-1 satellite before (April 24, 1992) and after (August 7, 1992) the earthquake, covering an area of dimensions $90 \mathrm{~km}$ by $110 \mathrm{~km}$ (Fig. 8f, top). The SAR interferogram provides a denser spatial sampling (100 m per pixel) than ground-based surveying methods and a better 


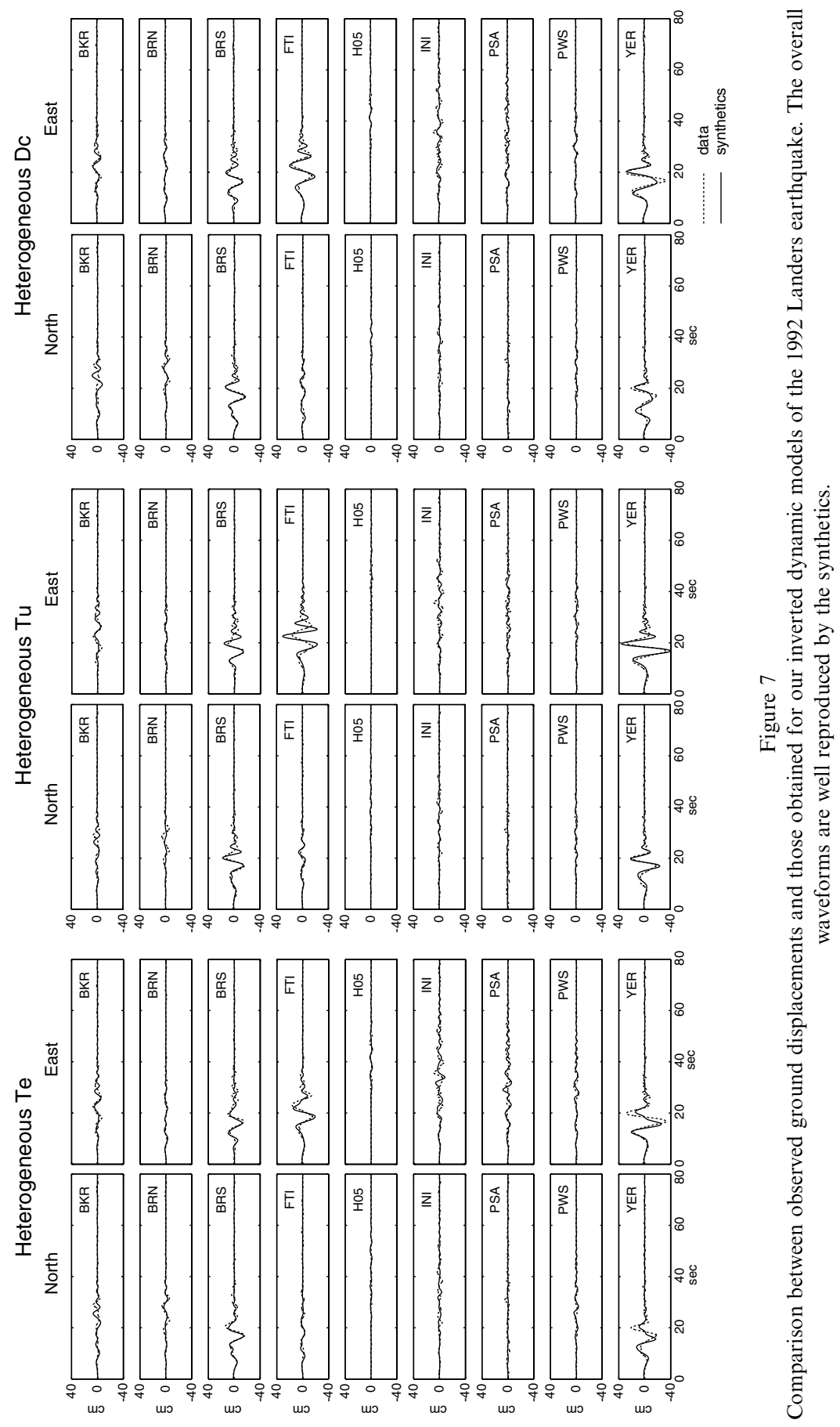


precision $(\sim 3 \mathrm{~cm})$ than previous space imaging techniques. The resulting interferogram (Fig. 8f, top) is a contour map of the change of range, i.e., the component of the displacement which points toward the satellite. Each fringe (one interval of color from the red to the blue) corresponds to one cycle, equivalent to $28 \mathrm{~mm}$ (half the wavelength of the ERS-1 satellite).

In order to test the resolution of InSAR and GPS data to constrain rupture parameters, we computed the three-component area-wide distribution of ground displacement (Figs. 8a-c, top) from the slip distribution (Figs. 5a-c) for our three dynamic rupture models using ОкаDA (1985)'s formulation. For comparison we show the response of a reference model with constant slip computed as the mean of the distributions generated by the asperity model (Fig. 8d, top), and a model with the slip distribution of the asperity model projected onto three segments (Fig. 8e, top). The overall shape of the fringes for the single-segment asperity and barrier models is well reproduced (Figs. 8a-c, top), while the more realistic three-segment model (Fig. 8e, top) shows an improved fit to the data. The agreement between the threesegment synthetic and observed interferograms is satisfactory except for the effects of the M 6.2 Big Bear event which occurred on the same day as the Landers earthquake are not included in the models. Thus, our results show that InSAR data provide a constraint on the geometry of the fault. Furthermore, the shape and amplitude of the fringes for the synthetic interferograms from a constant slip distribution (Fig. 8d, top) are much smoother and smaller, respectively, compared to those generated by the more realistic heterogeneous model. Therefore, the modeling of SAR interferograms provides a constraint on the spatial variation of the slip distribution. We find the same conclusions from similar models of horizontal GPS data (Fig. 8, bottom). Moreover, as shown in Figure 9, the slip distribution along the surface rupture produced by our dynamic models agrees well with the field data of surface displacement (HaUksSon, 1994; SieH et al., 1993). In summary, we find it to be important to include seismic, geodetic and field data to obtain the strongest constraints on the dynamic rupture parameters.

\section{Discussion and Conclusions}

We have constructed three well-posed mechanical models, an asperity and two barrier models of the Landers event, which generate synthetics in agreement with strong motion, GPS, InSAR, and field data, confirming an earlier hypothesis that seismic data cannot distinguish between barriers and asperities (see MADARIAGA, 1979). For all models the mode of rupture propagation from the initial asperity patch, the rupture speed, and the healing are critically determined by the distribution of prestress and the friction parameters. Therefore, a critical balance between initial stress and the frictional parameters must be met in order to generate a rupture history which produces synthetics in agreement with data. The barrier and asperity 
(a) Asperity model

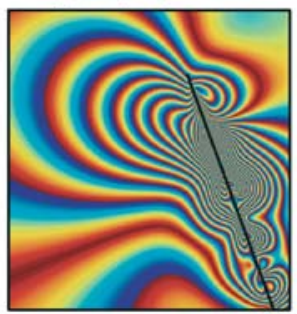

(d) Constant model

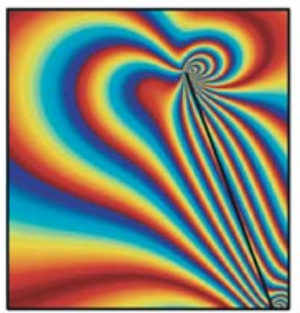

(a) Asperity model

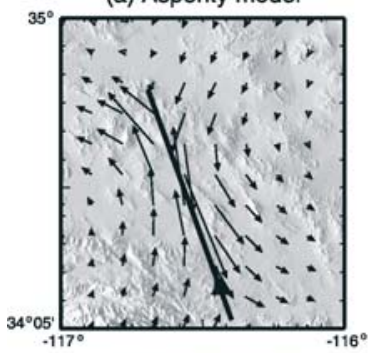

(d) Constant model

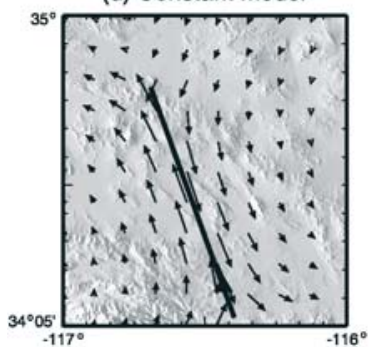

(b) Barrier model, Tu variable

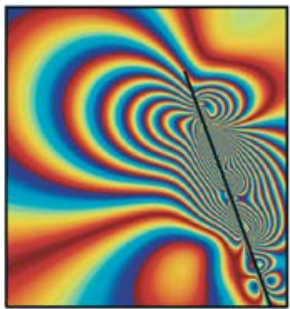

(e) Asperity model, 3 segments

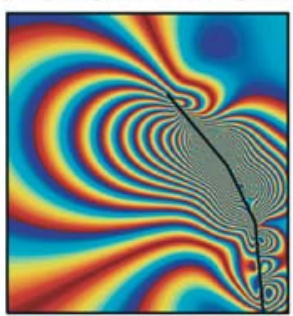

(b) Barrier model, Tu Variable

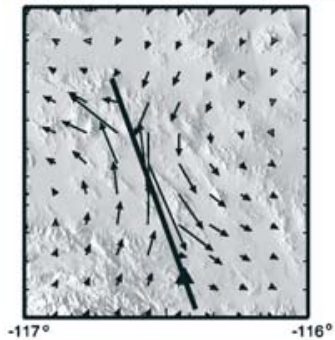

(e) Asperity model, 3 segments

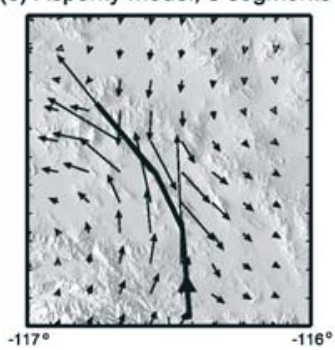

(c) Barrier model, Dc variable

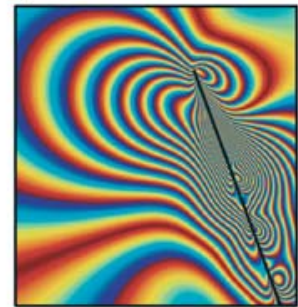

(f) InSAR data

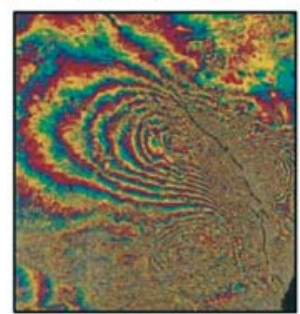

(c) Barrier model, Dc Variable

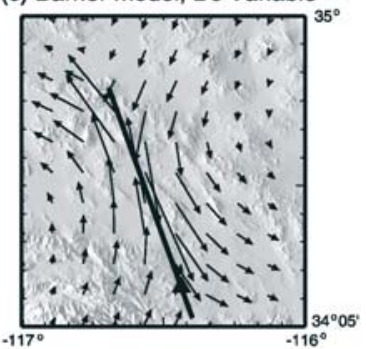

(f) Data

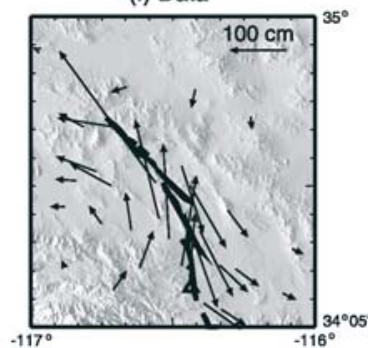

Figure 8

(Top) (a-e) Synthetic interferograms calculated on a rectangular grid with $200 \mathrm{~m}$ spacing for the Landers earthquake. (f) Observed coseismic interferogram covering a 90 by $110 \mathrm{~km}$ area measured between April 24 and August 7, 1992 (MAssonnet et al., 1993). Each cycle of the interferogram colors (red to blue) represents $28 \mathrm{~mm}$ of ground motion in the direction of the satellite. Black segments depict the fault geometry for each model. (Bottom) (a-e) Predicted horizontal GPS displacements calculated for the Landers earthquake depicted by arrows on a regular grid. (f) Observed horizontal displacements at GPS sites and USGS trilateration stations (Hudnut et al., 1994; Murray et al., 1993). 


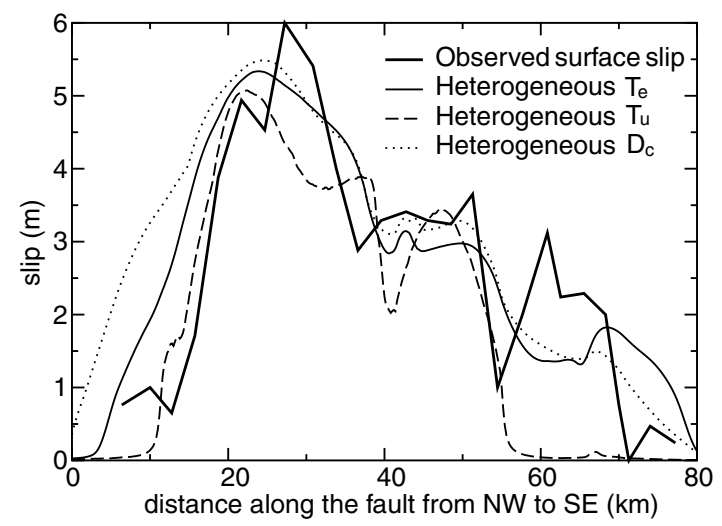

Figure 9

Comparison of simulated surface slip along the fault for the three dynamic models and the observed slip for the Landers earthquake (HAUKSSON, 1994; SiEH et al., 1993).

models were related using the non-dimensional parameter $\kappa$, where we assumed a constant value of the characteristic length scale $W$ (MADARIAGA and OlsEN, 2000). In order to examine this assumption we calculated the distributions of $\kappa$ for the three models (Fig. 6, bottom). The distribution of $\kappa$ is somewhat similar for the asperity model and barrier model with variable $T_{u}$, but differs considerably for the barrier model with variable $D_{c}$. This result may be due to the nature of the heterogeneous parameters (stress versus distance) in the three models but further supports the view that $W$ varies across the fault for heterogeneous rupture models. $W$ is very likely a measure of the correlation length of the heterogeneities. Future efforts should focus on estimating the (spatially variable?) $W$ that allows $\kappa$ to connect dynamic barrier to asperity rupture models.

There are no major differences between the three models of the Landers earthquake in terms of the capacity to reproduce observed data, even though the initial conditions, and therefore their physical interpretation, are completely different. The three models are end-members of a large family of dynamically correct models. It is important to point out that we see no clear indications in the data as to which model is better, and the true rupture for the Landers earthquake is likely a combination of these models. Thus we have demonstrated that the solution of the dynamic problem is not unique, and it may not be possible to separate strength drop and $D_{c}$ using rupture modeling with current bandwidth limitations, in agreement with the conclusions by GuATTERI and SPUDICH (2000). However, the inclusion of higher frequency components from high-resolution near-field records of large earthquakes may enable their separation in the future by increasing the resolution of the model. Furthermore, we realize that dynamic parameters are relatively poorly constrained, and additional information on stress drop and the nature of the friction law should be obtained by different methods, such as borehole 
drilling or laboratory experiments. Finally, geodetic and field data may be used to further constrain the rupture propagation parameters in future studies. For example, geodetic data can provide important constraints on the slip distribution and geometry of the fault, in particular in the absence of surface rupture.

\section{Acknowledgements}

This research was supported by grants from the project "Modélisation des séismes et changement d'échelles" from the ACI Prévention des catastrophes naturelles from the Ministère de la Recherche, and by NSF (EAR0003275), University of California at Sarta Barbara, Los Alamos National Laboratories, and the Southern California Earthquake Center. SCEC is funded by NSF Cooperative Agreement EAR-0106924 and USGS Cooperative Agreement 02HQAG0008. The SCEC contribution number for this paper is 720 , and the ICS contribution number is 556. The computations in this study were carried out on the SUN Enterprise at MRL/ICS and on the facilities of the Département de Modélisation Physique et Numérique of the Institut de Physique du Globe de Paris.

\section{REFERENCES}

Beroza, G. C. and Mikumo, T. (1996), Short Slip Duration in Dynamic Rupture in the Presence of Heterogeneous Fault Properties, J. Geophys. Res. 101, 22,449-22,460.

DAs, S. and AKI, K. (1977), A Numerical Study of Two-dimensional Spontaneous Rupture Propagation, Geophys. J. Roy. Astr. Soc. 50, 643-668.

Dunham, E. M., Favreau, P., and Carlson, J. M. (2003), A Supershear Transition Mechanism for Cracks, Science 299, 1557-1559.

Guatteri, M. and Spudich, P. (2000), What Can Strong-motion Data Tell Us about Slip-weakening Faultfriction Laws?, Bull. Seismol. Soc. Am. 90, 98-116.

Hauksson, E. (1994), State of Stress from Focal Mechanisms Before and After the 1992 Landers Earthquake Sequence, Bull. Seismol. Soc. Am. 84, 917-934.

Hernandez, B., Cotton, F., and Campillo, M. (1999), Contribution of Radar Interferometry to a Twostep Inversion of the Kinematic Process of the 1992 Landers Earthquake, J. Geophys. Res. 104, 13,08313,099 .

Hudnut, K. W., Bock, Y., Cline, M., Fang, P., Feng, Y., Freymueller, J., Ge, X., Gross, W. K., Jackson, D., Kim, M., King, N. E., Langbein, J., Larsen, S. C., Lisowski, M., Shen, Z. K., Svarc, J., and Zhang, J. (1994), Co-seismic Displacements of the 1992 Landers Earthquake Sequence, Bull. Seismol. Soc. Am. 84, 625-645.

IDA, Y. (1972), Cohesive Force Across the Tip of a Longitudinal-shear Crack and Griffith's Specific Surface Energy, J. Geophys. Res. 77, 3796-3805.

Ide, S. and Takeo, M. (1997), Determination of Constitutive Relations of Fault Slip Based on Seismic Wave Analysis, J. Geophys. Res. 102, 27,379-27,391.

Kanamori, H. and Stewart, G. S. (1978), Seismological Aspects of the Guatemala Earthquake of February 4, 1976, J. Geophys. Res. 83, 3427-3434.

Madariaga, R. (1979), On the Relation Between Seismic Moment and Stress Drop in the Presence of Stress and Strengh Heterogeneity, J. Geophys. Res. 84, 2243-2250. 
Madariaga, R., Olsen, K., and Archuleta, R. (1998), Modeling Dynamic Rupture in a 3-D Earthquake Fault Model, Bull. Seismol. Soc. Am. 88, 1182-1197.

Madariaga, R. and Olsen, K. B. (2000), Criticality of Rupture Dynamics in 3-D, Pure Appl. Geophys. 157, 1981-2001.

Massonnet, D., Rossi, M., Carmona, C., Adragna, F., Peltzer, G., Feigl, K., and Rabaute T. (1993), The Displacement Field of the Landers Earthquake Mapped by Radar Interferometry, Nature 364, 138-142.

Murray, M. H., Savage, J. C., Lisowski, M., and Gross, W. K. (1993), Coseismic Displacements: 1992 Landers, California, Earthquake, Geophys. Res. Lett. 20, 623-626.

OkadA, Y. (1985), Surface Deformation Due to Shear and Tensile Faults in a Half-space, Bull. Seismol. Soc. Am. 75, 1135-1154.

Olsen, K. B., Madariaga, R., and Archuleta, R. J. (1997), Three-dimensional Dynamic Simulation of the 1992 Landers Earthquake, Science 278, 834-838.

Peyrat, S., Madariaga, R., and Olsen, K. (2002), La Dynamique des Tremblements de Terre Vue à Travers le Séisme de Landers du 28 Juin 1992, C. R. Acad. Sci., Mécanique 330, 235-248.

Peyrat, S., Olsen, K., and Madariaga, R. (2001), Dynamic Modeling of the 1992 Landers Earthquake, J. Geophys. Res. 106, 26,467-26,482.

Sieh, K., Jones, L., Hauksson, E., Hudnut, K., Eberhart-Phillips, D., Heaton, T., Hough, S., Hutton, K., Kanamori, H., Lilje, A., Lindvall, S., McGill, S. F., Mori, J., Rubin, C., Spotila, J. A., Stock, J., Thio, H. K., Treiman, J., Wernicke, B., and Zachariasen J. (1993), Nearfield Investigations of the Landers Earthquake Sequence, April to July 1992, Science 260, 171-176.

Wald, D. J. and Heaton, T. H. (1994), Spatial and Temporal Distribution of Slip for the 1992 Landers, California, Earthquake, Bull. Seismol. Soc. Am. 84, 668-691.

(Received September 27, 2002, revised April 25, 2003, accepted May 15, 2003)

(1) To access this journal online: http://www.birkhauser.ch 